\title{
Patient Centeredness in Hepatitis C Direct-Acting Antiviral Treatment Delivery to People Who Inject Drugs: A Scoping Review
}

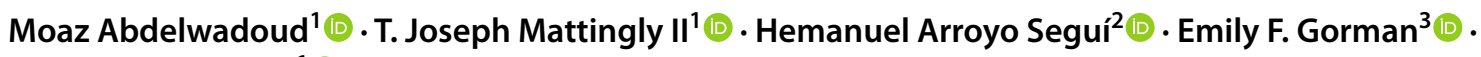 \\ Eleanor M. Perfetto ${ }^{1}[$
}

Accepted: 28 November 2020 / Published online: 29 December 2020

(c) The Author(s) 2020

\begin{abstract}
Background and Objective Patient-centered care (PCC) is crucial for value-based care. We aimed to assess PCC dimensions addressed in hepatitis $\mathrm{C}$ virus direct-acting antiviral treatment delivery to people who inject drugs.

Methods We conducted a scoping review to identify the studies that described hepatitis $C$ virus treatment delivery to people who inject drugs in the direct-acting antiviral treatment era. We analyzed the included studies against eight PCC dimensions: (1) access to care; (2) coordination and integration of care; (3) continuity and translation; (4) physical comfort; (5) information, education, and communication; (6) emotional support; (7) involvement of family and friends; and (8) respect for individual patient preferences, perceived needs, and values. Additionally, we assessed the use of patient-centered terminology and the recognition of PCC importance and its relevance to treatment outcomes.

Results None of the identified 36 studies addressed all PCC dimensions (highest seven, lowest two). Our findings revealed that PCC dimensions are prioritized differently and addressed using different approaches and strategies. Studies that used PCC terminology referred to personalized activities, which does not imply comprehensive PCC. About one-third of the studies acknowledged the importance of patient centeredness and two-thirds recognized its relevance to treatment outcomes. Conclusions Our findings suggest more engagement of people who inject drugs and comprehensive involvement of their families and friends in hepatitis C virus treatment journey, decisions, and outcomes. The recognition of PCC importance and its relevance to treatment outcomes in the analyzed studies emphasizes the need for more patient-centered hepatitis $\mathrm{C}$ virus treatment for people who inject drugs.
\end{abstract}

\section{Introduction}

People who inject drugs (PWID) are the most at-risk group for hepatitis $\mathrm{C}$ virus (HCV) infection and are responsible for a large proportion of transmission. Approximately $23 \%$ of

Supplementary Information The online version contains supplementary material available at https://doi.org/10.1007/s4027 1-020-00489-6.

Moaz Abdelwadoud

mabdelwadoud@rx.umaryland.edu

1 Department of Pharmaceutical Health Services Research, University of Maryland School of Pharmacy, 220 Arch Street, 12th Floor, Baltimore, MD 21201, USA

2 University of Maryland School of Pharmacy, Baltimore, MD, USA

3 Health Sciences and Human Services Library, University of Maryland, Baltimore, MD, USA new $\mathrm{HCV}$ infections are attributed to injection drug use and about $8.5 \%$ of the world's chronic $\mathrm{HCV}$-infected people are recent injection drug users $[1,2]$. In 2013, about 700,000 deaths worldwide were attributable to $\mathrm{HCV}$-related liver cirrhosis and hepatocellular carcinoma [3], and approximately one-third of those deaths are related to injection drug use [4].The inclusive definition of PWID includes all persons who practiced injection of an illicit drug at least once in their life. Injectors are classified into "former" and "recent", where the definition of recency varies across different classifications from 1 month to 1 year [5].

The expectation of HCV elimination after the introduction of highly effective, direct-acting antiviral (DAA) treatment has been hindered by several real-life obstacles in the interventions targeting PWID treatment delivery. These obstacles revolve around injection drug use, sociobehavioral problems, and ineffective access to care. The main socio-behavioral obstacles include stigmatization and its associated discomfort at conventional healthcare settings and incarceration. Access to care obstacles include: 


\section{Key Points for Decision Makers}

This scoping review identified and assessed the inclusion of different dimensions of patient-centered care (PCC) in hepatitis $\mathrm{C}$ virus (HCV) treatment delivery to people who inject drugs (PWID) during the direct-acting antiviral era. It also assessed how the included studies recognized patient centeredness and reported on its relevance to treatment outcomes.

The analyzed studies incorporated the dimensions of PCC using different approaches and strategies, however; none of them could include all eight dimensions.

The recognition of PCC importance and its relevance to treatment outcomes emphasizes the need for more patient-centered PWID HCV treatment delivery.

Future HCV treatment delivery studies should detail how treatment services are provided and assess PWID HCV treatment experiences and reported outcomes for better understanding of direct-acting antiviral clinical outcomes and their real-world attributions.

(1) multiple medical problems including co-infection with human immunodeficiency virus (HIV) and hepatitis B virus; (2) challenges in linkage to HCV specialty care and treatment initiation; (3) inadequate adherence to long-term treatment plans; and (4) lack of follow-up after treatment completion for sustained virologic response (SVR) and reinfection assessments [6, 7].

In parallel to the pressing $\mathrm{HCV}$ burden, there is a growing worldwide agreement on the necessity of a patient-centered care (PCC) approach to deliver value-based care [8]. Since the early 2000 s, leading international and national governmental organizations have been fostering PCC including the World Health Organization (WHO) and the US Department of Health and Human Services [9]. The National Academy of Medicine, formerly the Institute of Medicine, recognizes PCC as one of the six domains of quality care and defines it as: "care that is respectful of and responsive to individual patient preferences, needs, and values; and ensures that patient values guide all clinical decisions" [10]. Patient centeredness engages individual patients in healthcare provision and guides decision making by including their needs and values, experiences of illness and care, and other psychosocial contexts [11].

The WHO guidelines on the care and treatment of chronic $\mathrm{HCV}$ recommend simplification of treatment delivery, integration with primary services or other services supporting HCV patients' needs, task shifting to primary providers with specialist support as needed, and engaging communities to address stigma and support HCV outreach activities [12]. In particular, task shifting and expansion of $\mathrm{HCV}$ treatment to primary care and community-based settings have been proved effective in improving access and adherence to treatment among PWID [7]. Combining HCV DAA treatment with medication-assisted treatment or syringe exchange programs has been recognized as a best practice in comprehensive care for PWID [13]. Modeling studies estimate that a single decade of successful implementation of this integration would lead to more than a 50\% reduction in $\mathrm{HCV}$ prevalence and transmission among PWID [14]. Integration and co-location of HCV DAA, medication-assisted treatment, and syringe exchange programs for PWID have been implemented under different methods of care designs and at different settings, for example, community health centers, substance abuse management (SAM) centers, primary care facilities, and prisons [15]. However, successful integration and scaling up have several implementation challenges hidden in the details of how services are provided and to what extent the patient is engaged [14]. A review study on HCV treatment methods of care delivery identified that key data gaps exist in the types and teams of providers, care delivery details, provider-patient interactions, and factors underneath the successes and failures within HCV care delivery [16].

Despite the vast amount of literature on DAA clinical effectiveness, the role of PCC in HCV treatment delivery to PWID in the new DAA era is unknown. Thus, the objectives of this scoping review are to: (1) identify and assess the dimensions of PCC in the studies that described HCV DAA treatment delivery to PWID and (2) assess the use of patientcentered terminology in these studies, acknowledgment of PCC importance, and its relevance to treatment outcomes. The results of this review should help guide healthcare providers and policy makers in developing effective patient-centered strategies and delivery methods to support elimination of $\mathrm{HCV}$ among this vulnerable population group.

\section{Methods}

\subsection{Search Strategy}

Our systematic search followed the guidance from the PRISMA Extension for Scoping Reviews (PRISMA-ScR) [17]. The search strategy was developed in consultation with an experienced health sciences librarian (E.G.). Searches were conducted using the following bibliographic databases: PubMed (Pubmed.gov), Embase (Embase.com), CINAHL (EBSCOhost), PsycINFO (EBSCOhost), the Cochrane Library (Wiley Online; includes the Cochrane Database of Systematic Reviews, the Cochrane Central Register of 
Controlled Trials, and Cochrane Clinical Answers), and registered studies in ClinicalTrials.gov. The search terms were informed by a previous systematic review that evaluated the clinical effectiveness of HCV DAA among PWID [18]. The search strategy involved combinations of keywords and subject headings adapted to the specifications of each database, and relevant filters were used to restrict the results to literature published since January 2014. Search results included at least one term from each of the following concept areas: treatment interventions (including DAA), injecting drugs, and hepatitis C. The full strategies for the original search (February 2019) and its update (October 2019) are available in the Electronic Supplementary Material (ESM).

\subsection{Eligibility Criteria}

We included original research of observational and experimental studies and protocols that met all the following criteria: (1) described a specific HCV treatment delivery method for DAA alone or in combination with ribavirin or pegylated interferon; (2) included PWID among its participants; and (3) had an abstract and full text available in English. Given the US Food and Drug Administration (FDA) approval for interferon-free therapy using the second-generation DAAs in December 2013, included studies were limited to those published between January 2014 and September 2019. We conducted our study between February 2019 and May 2020.

\subsection{Study Selection and Data Extraction}

Two reviewers (M.A. and H.A.) independently screened and assessed the resulting studies for relevance using Rayyan ${ }^{\circledR}$ Software [19] in two consequent phases: titles and abstracts screening, followed by full-text review of studies that appeared to meet criteria based on the first screen. Disagreements between the two reviewers were resolved by a third reviewer (J.M.) to achieve a final consensus on the included studies. Final included studies' characteristics were organized in a Microsoft Excel ${ }^{\circledR}$ data extraction sheet.

\subsection{Assessment of Study Patient-Centeredness Characteristics}

Included studies were assessed according to (a) PCC dimensions featured in their treatment delivery and (b) recognition of patient centeredness. We followed the eight PCC dimensions developed by The Picker Commonwealth Program for PCC, which later became the Picker Institute. These dimensions were concluded via patient-driven research and included: (1) access to care; (2) coordination and integration of care; (3) continuity and translation of care; (4) physical comfort; (5) information, education, and communication; (6) emotional support; (7) involvement of family and friends; and (8) respect for individual patient preferences, perceived needs, and values (Table 1) [20,21]. With respect to individual patient preferences, perceived needs, and values, shared decision making has been identified as an overarching principle for PCC [10]. Patient involvement in decision making is mandatory to differentiate between refusal of treatment and non-adherence, where the latter occurs only if there is a mutual agreement between the patient and the provider on the treatment plan [22]. In addition to the eight dimensions, we assessed the studies' recognition of patient centeredness that included: (1) use of patient-centered terminology; (2) acknowledgment of patient centeredness importance in treatment delivery; and (3) reporting on DAA outcomes in relevance to patient centeredness. Description of PCC dimension components and recognition elements are presented in Table 1. We also extracted the following characteristics of the included studies: author(s), year of publication, country, study location (city/province/state), study period, study title/ project name, study setting, study design, study methods, study aim(s), study primary outcome, and participants' characteristics in relevance to drug use.

\section{Results}

\subsection{Search Results}

The six-database search yielded a total of 9288 studies. After de-duplication, we screened 6053 studies using title and abstract screening out of which 5996 were excluded. Full-text assessment of the remaining 57 studies resulted in 36 studies meeting our eligibility criteria, and accordingly included in our analysis (Fig. 1).

\subsection{Studies' Characteristics}

Studies' characteristics (Table 2) revealed that most studies were recently published with 23,5 , and 7 studies in 2019 , 2018 , and 2017 , respectively and only one study was published in 2015. Half of the studies were conducted in North America, nine studies were conducted in Europe, eight studies were conducted in Australia and New Zealand, and one study was conducted in Asia with no studies in Africa. Studies' settings spanned: primary care centers (7 studies), SAM centers (6 studies), HIV clinics, homeless care centers, syringe exchange programs, correctional facilities, university hospitals, Veterans Affairs hospitals, departments of public health, local pharmacies, and specialized clinics. The designs of the analyzed studies included observational: cohort, case control, and cross-sectional; and experimental: randomized and non-randomized clinical trial designs. The aims of the included studies ranged widely and most of them had multiple aims. Most studies had aims related to 
Table 1 Description of patient-centeredness dimensions and recognition elements

\begin{tabular}{|c|c|}
\hline Patient-centeredness dimension & Description of dimension component(s) $[21,72]$ \\
\hline Access to care & $\begin{array}{l}\text { Geographical accessibility to services } \\
\text { Waiting times and ease of scheduling appointments } \\
\text { Linkage to specialty services on referral }\end{array}$ \\
\hline Coordination and integration of care & $\begin{array}{l}\text { Coordinated care: focuses on communication between different services } \\
\text { Example: coordination of patient care between primary and specialty care providers who work at } \\
\text { separate facilities and have separate systems } \\
\text { Co-located care: focuses on physical proximity } \\
\text { Example: primary and specialty care providers are co-located in the same facility } \\
\text { Integrated care: emphasizes practice change } \\
\text { Example: primary and specialty services are provided by one team who share the same treatment } \\
\text { plan. Most integrated care models integrate specialty services within community-based primary } \\
\text { care facilities }\end{array}$ \\
\hline Continuity and translation & $\begin{array}{l}\text { Understandable medical, social, physical, and financial support information } \\
\text { Follow-up and adherence support for required clinical visits } \\
\text { Coordinated HCV treatment plan with other services } \\
\text { Continuity after completing HCV treatment }\end{array}$ \\
\hline Physical comfort & $\begin{array}{l}\text { Assistance with daily activities and living needs } \\
\text { Pain management }\end{array}$ \\
\hline Information, education, and communication & $\begin{array}{l}\text { Information on clinical status, disease progress and prognosis, and processes of care } \\
\text { Information to facilitate autonomy, self-care, and health promotion }\end{array}$ \\
\hline Emotional support & $\begin{array}{l}\text { Reassurance and alleviating anxiety over clinical status; treatment; prognosis; impact of the illness } \\
\text { on patients and their family, and the financial impact of their illness }\end{array}$ \\
\hline Involvement of family and friends & $\begin{array}{l}\text { Addressing the patient family and friends' needs in terms of: } \\
\text { Accommodation to treatment including education and adherence } \\
\text { Protection including HCV screening } \\
\text { Supporting caregiving } \\
\text { Involvement in treatment evaluation }\end{array}$ \\
\hline $\begin{array}{l}\text { Respect for individual patient preferences, } \\
\text { perceived needs, and values }\end{array}$ & $\begin{array}{l}\text { Respect for the patient cultural values and autonomy } \\
\text { Focusing on the individual patient needs via personalized education, adherence, and treatment plan } \\
\text { Shared decision making }\end{array}$ \\
\hline Patient-centeredness recognition element & Description of recognition element \\
\hline Use of patient-centeredness terminology & Use of either "patient-centered" or "patient-centred" term in describing activities \\
\hline Acknowledgment of patient centeredness & $\begin{array}{l}\text { Authors' acknowledgment of patient-centeredness dimensions importance in their treatment } \\
\text { intervention }\end{array}$ \\
\hline $\begin{array}{l}\text { Specific relevance of patient centeredness to } \\
\text { treatment outcomes }\end{array}$ & Authors' reporting on the relevance of patient centeredness to DAA treatment outcomes \\
\hline
\end{tabular}

$D A A$ direct-acting antiviral, $H C V$ hepatitis $\mathrm{C}$ virus

their treatment delivery feasibility, effectiveness, or influencing factors. Most primary outcomes of the included studies revolved around quantification of $\mathrm{HCV}$ treatment continuum rates: screening, linkage to care, treatment adherence, treatment completion, SVR, and reinfection. Some studies did not describe their participants' characteristics in relevance to injection drug use. A full description of these characteristics is demonstrated in the ESM.

\subsection{Patient-Centeredness Dimensions and Their Components in the Included Studies}

While the primary objectives of the included studies were not focusing on addressing PCC in their treatment delivery, 36 studies included a range between two and seven of the eight dimensions of PCC (Table 3). Four studies included two dimensions, nine included three dimensions, ten included four dimensions, nine included five dimensions, three included six dimensions, and one study included seven dimensions. The most included dimension was "coordination and integration of care" in 35 studies, while the least included was "involvement of family and friends" in five studies.

\subsubsection{Access to Care}

Fourteen studies addressed access to care under three activities: 


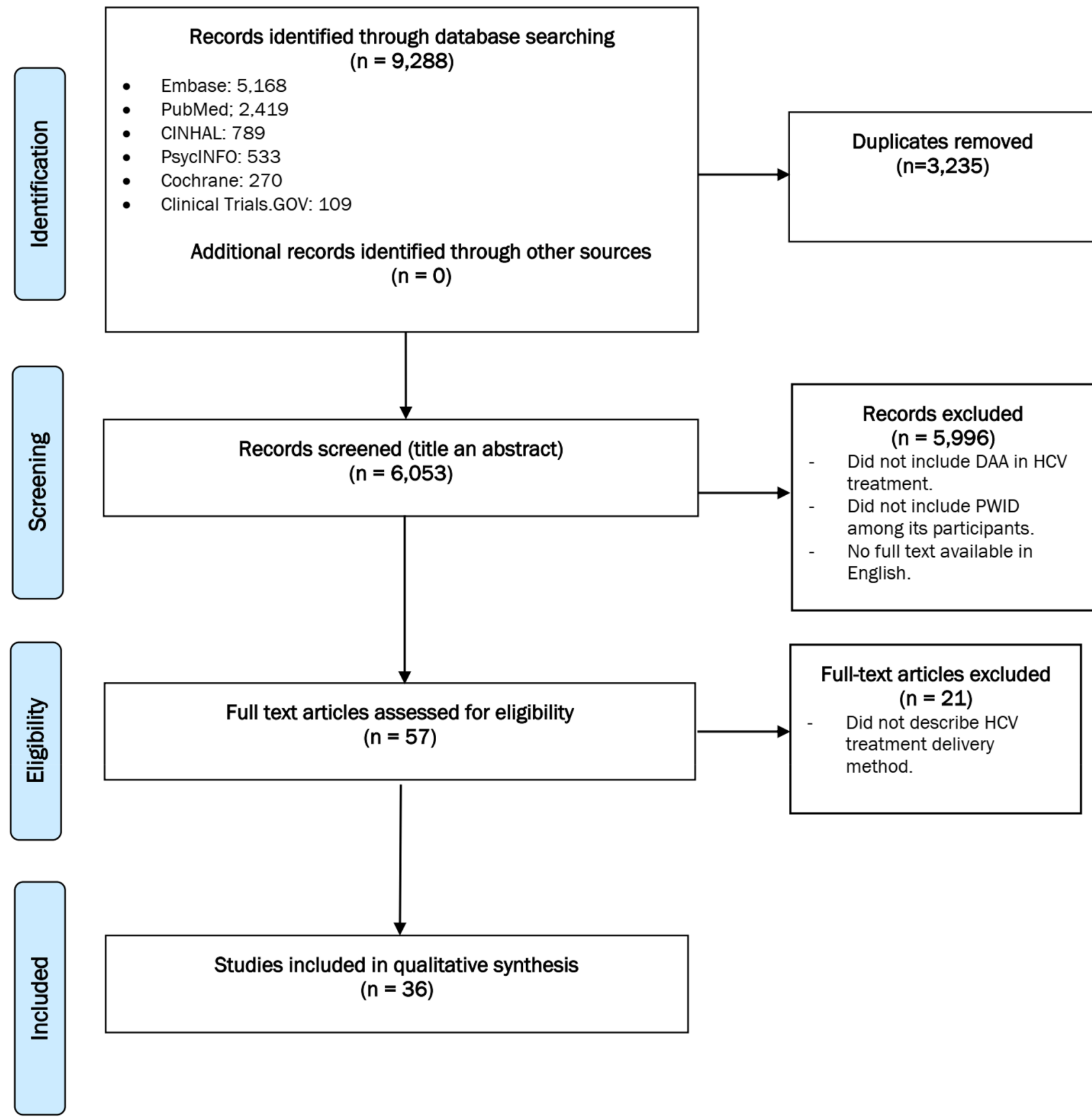

Fig. 1 PRISMA (Preferred Reporting Items for Systematic Reviews and Meta-Analyses) flow diagram of the search and study selection process. $D A A$ direct-acting antiviral, $H C V$ hepatitis $\mathrm{C}$ virus, $P W I D$ people who inject drugs

3.3.1.1 Geographical Accessibility Ten studies addressed geographical accessibility to DAA treatment and followup visits via offering free public transportation passes for HCV appointments [23], providing special transportation to $\mathrm{HCV}$ treatment facilities for patients living in remote areas [24], providing $\mathrm{HCV}$ treatment at community pharmacies [25] and homelessness services [26], or task shifting to primary providers with telemedicine support in remote areas
[27-29] or prisons [30]. One study coordinated medication delivery with collaborating organizations to prisons, police cells, psychiatric units, and hospitals [31], and another study supported homeless patients' attendance of medical appointments [32].

3.3.1.2 Scheduling Appointments Five studies provided scheduling assistance in different ways: assisting with 
Table 2 Summary of included studies' characteristics

\begin{tabular}{|c|c|c|}
\hline Characteristic & & \multirow{2}{*}{$\begin{array}{l}\begin{array}{l}\text { Number } \\
\text { of studies } \\
(n=36)\end{array} \\
23\end{array}$} \\
\hline Year of publication & 2019 & \\
\hline & 2018 & 5 \\
\hline & 2017 & 7 \\
\hline & 2015 & 1 \\
\hline \multirow[t]{8}{*}{ Country } & USA & 16 \\
\hline & Australia and New Zealand & 8 \\
\hline & UK & 5 \\
\hline & Canada & 2 \\
\hline & Georgia & 2 \\
\hline & France & 1 \\
\hline & India & 1 \\
\hline & Italy & 1 \\
\hline \multirow[t]{16}{*}{ Study setting } & Primary care center & 7 \\
\hline & Substance abuse management center & 6 \\
\hline & HIV clinic & 3 \\
\hline & Homeless care center & 3 \\
\hline & Harm reduction and syringe exchange program & 2 \\
\hline & Correctional facility & 2 \\
\hline & University hospital & 2 \\
\hline & Veterans Affairs hospital & 2 \\
\hline & Department of Public Health & 1 \\
\hline & Local pharmacy & 1 \\
\hline & Specialized HCV or infectious disease clinic & 1 \\
\hline & Harm reduction program + specialized $\mathrm{HCV}$ or infectious disease clinic & 3 \\
\hline & Substance abuse management center + primary care center & 1 \\
\hline & Substance abuse management center + university hospital & 1 \\
\hline & Primary care center + university hospital & 1 \\
\hline & Homeless care center + university hospital & 1 \\
\hline \multirow[t]{7}{*}{ Study design } & Observational & \\
\hline & Cohort & 23 \\
\hline & Case-control & 1 \\
\hline & Cross-sectional & 2 \\
\hline & Experimental & \\
\hline & Randomized controlled trials & 8 \\
\hline & Non-randomized controlled trials & 2 \\
\hline \multirow[t]{9}{*}{ Study aim $(\mathrm{s})^{\mathrm{a}}$} & Assessing HCV and liver disease burden among target population & 2 \\
\hline & Identifying social experiences and motivations of PWID for HCV treatment & 1 \\
\hline & Assessing the safety and efficacy of DAA treatment in PWID & 2 \\
\hline & Assessing the impact of drug use and substance abuse management on HCV treatment outcomes & 1 \\
\hline & Describing treatment intervention model & 4 \\
\hline & Assessing the feasibility of treatment intervention model & 7 \\
\hline & $\begin{array}{l}\text { Assessing the effectiveness of treatment intervention in engaging patients with testing, linkage to care, } \\
\text { treatment adherence, treatment completion, SVR, and reinfection prevention }\end{array}$ & 24 \\
\hline & $\begin{array}{l}\text { Assessing the factors influencing linkage to HCV care, treatment adherence, treatment completion, and } \\
\text { SVR }\end{array}$ & 7 \\
\hline & Assessing patient satisfaction with the treatment intervention model & 1 \\
\hline
\end{tabular}


Table 2 (continued)

\begin{tabular}{lll}
\hline Characteristic & & $\begin{array}{c}\text { Number } \\
\text { of studies } \\
(n=36)\end{array}$ \\
\hline Study primary outcome & $\begin{array}{l}\text { Quantification of HCV treatment continuum rates: screening, linkage to care, treatment adherence, } \\
\text { treatment completion, SVR, and reinfection }\end{array}$ \\
& Efficacy of peer engagement & 33 \\
& Characteristics of patients who did not achieve SVR & 1 \\
& Social incentives of PWID on HCV treatment & 1 \\
Participants characteristics & Described & 29 \\
in relevance to drug use & Not described & 7 \\
\hline
\end{tabular}

$D A A$ direct-acting antiviral, $H C V$ hepatitis $\mathrm{C}$ virus, $H I V$ human immunodeficiency virus, $P W I D$ people who inject drugs, SVR sustained virologic response

${ }^{\text {a }}$ Some studies had more than one aim

clinical and laboratory follow-up visits [33] in addition to rescheduling missed visits [23], considering patients' preferences and other commitments [34], and co-scheduling follow-up appointments for SAM and HCV treatment on 1 day [35]. Appointment support included reminder calls $[33,34,36]$ in addition to escorting patients to the treatment facility [23].

3.3.1.3 Linkage to Specialty Services on Referral Three studies offered referral support to specialty services. One study offered referral to an infectious disease service via a consult [35], another study offered reminders for other supportive services [36], and the third study considered patients' preferences and commitments not only for their scheduled appointment but for referral appointments as well [34].

\subsubsection{Coordination and Integration of Care}

With an exception of one study [37], all studies addressed the coordination and integration dimension via following one of the following three models.

3.3.2.1 Coordination Seven studies coordinated HCV treatment with other clinical services. These services included: community-based primary care services either physically $[23,38]$ or virtually via telemedicine [27], patient in-place clinical facilities [23], emergency accommodation and homelessness services [32, 38], and specialized hepatology or infectious disease clinics [24, 39, 40].

3.3.2.2 Co-location Eleven studies co-located HCV treatment point of care with other services. These services included primary care services [36, 41, 42], homeless primary care services [26], SAM clinics [41, 43, 44], harm reduction centers [45-47], public health services [48], and HIV clinics [49].

3.3.2.3 Integration Seventeen studies modified clinical practices to integrate $\mathrm{HCV}$ treatment. Integration was implemented in primary care facilities [31, 33, 50-54], SAM services [28, 29, 34, 35, 55], syringe exchange programs [56], HIV clinics [57, 58], community pharmacies [25], and prisons [30].

\subsubsection{Continuity and Translation}

Twenty-three studies offered continuity and translation to their patients in three forms.

3.3.3.1 Understandable Medical, Social, Physical, and Financial Support Information One study offered general information about their study to their participants [26]. Three studies offered supportive information after visits including home administration of treatment [23, 50, 58].

\subsubsection{Follow-up and Adherence Support for Required} Clinical Visits Follow-up support to ensure adherence was the most addressed component within this dimension (19 studies). This follow-up was offered by providers [31, 33, $37,39,40,42,43,45,46,48,50-52,58]$ as well as peer support groups $[26,53,56]$. One study triaged the patients into different levels of support according to their risk of non-adherence and patients who did not complete treatment were offered intensive follow-up home visits by peers [57]. Another study provided cash incentives to a group of its patients to reinforce adherence to clinical visits [49].

3.3.3.3 Coordinated HCV Treatment Plan with Other Services Coordinating treatment plans was implemented by linking HCV services with medical and social services in 
Table 3 Distribution of patient centeredness dimensions and recognition elements in the analyzed studies

\begin{tabular}{|c|c|c|c|}
\hline Patient-centeredness dimension & Dimension component(s) & $\begin{array}{l}\text { Number of studies that } \\
\text { addressed each compo- } \\
\text { nent }\end{array}$ & $\begin{array}{l}\text { Total number of studies that } \\
\text { addressed the dimension } \\
(n=36)\end{array}$ \\
\hline \multirow[t]{3}{*}{ Access } & Geographical accessibility [23-32] & 10 & \multirow[t]{3}{*}{$14^{\mathrm{a}}$} \\
\hline & $\begin{array}{l}\text { Waiting times and scheduling appointments [23, } \\
33-36]\end{array}$ & 5 & \\
\hline & Linkage to specialty services [34-36] & 3 & \\
\hline \multirow[t]{3}{*}{ Coordination and integration } & Coordinated care $[23,24,27,32,38-40]$ & 7 & \multirow[t]{3}{*}{$35^{\mathrm{a}}$} \\
\hline & Co-located care $[26,36,41-49]$ & 11 & \\
\hline & Integrated care $[25,28-31,33-35,50-58]$ & 17 & \\
\hline \multirow[t]{4}{*}{ Continuity and translation } & Understandable information $[23,26,50,58]$ & 4 & \multirow[t]{4}{*}{$23^{\mathrm{a}}$} \\
\hline & $\begin{array}{c}\text { Follow-up and adherence support }[26,31,33 \text {, } \\
37,39,40,42,43,45,46,48-53,56-58]\end{array}$ & 19 & \\
\hline & $\begin{array}{l}\text { Coordinated HCV treatment plan with other } \\
\text { services }[31,33,35,39,40,43,51]\end{array}$ & 7 & \\
\hline & $\begin{array}{l}\text { Continuity after completing HCV treatment [23, } \\
37,39,44,48,56]\end{array}$ & 6 & \\
\hline \multirow[t]{2}{*}{ Physical comfort } & $\begin{array}{l}\text { Assistance with daily activities }[23,26,31-33 \text {, } \\
35,37,39,44,45,47,52,53,58]\end{array}$ & 14 & \multirow[t]{2}{*}{14} \\
\hline & Pain management & 0 & \\
\hline \multirow[t]{2}{*}{ Information \& education } & $\begin{array}{l}\text { Information on clinical status, disease progress } \\
\text { and prognosis, and processes of care [23-25, } \\
27-30,32,34-36,38,39,41,42,44-47 \text {, } \\
49-53,55]\end{array}$ & 25 & \multirow[t]{2}{*}{25} \\
\hline & $\begin{array}{l}\text { Information to facilitate autonomy, self-care, } \\
\text { and health promotion }\end{array}$ & 0 & \\
\hline Emotional support & $\begin{array}{l}\text { Reassurance and alleviating anxiety [26, } 29, \\
32-37,39,41,45,47-51,53,56,57]\end{array}$ & 20 & 20 \\
\hline \multirow[t]{4}{*}{ Involvement of family and friends } & Accommodation to treatment $[23,27]$ & 2 & \multirow[t]{4}{*}{$5^{\mathrm{a}}$} \\
\hline & Protection including HCV screening $[24,55]$ & 2 & \\
\hline & Supporting caregiving & 0 & \\
\hline & $\begin{array}{l}\text { Involvement in treatment evaluation [55] } \\
\text { Unspecified "buddy" involvement [34] }\end{array}$ & $\begin{array}{l}1 \\
1\end{array}$ & \\
\hline \multirow{3}{*}{$\begin{array}{l}\text { Respect for individual patient } \\
\text { preferences, perceived needs, and } \\
\text { values }\end{array}$} & $\begin{array}{l}\text { Respect for the patient cultural values and } \\
\text { autonomy }\end{array}$ & 0 & \multirow[t]{3}{*}{9} \\
\hline & $\begin{array}{l}\text { Focusing on the individual patient needs [ } 31 \text {, } \\
36,45,46,51,52,57,58]\end{array}$ & 8 & \\
\hline & Shared decision making [35] & 1 & \\
\hline \multicolumn{3}{|c|}{ Patient-centeredness recognition element } & $\begin{array}{l}\text { Total number of studies that } \\
\text { addressed the recognition } \\
\text { element }\end{array}$ \\
\hline \multicolumn{3}{|c|}{ Use of patient-centeredness terminology $[35,53,54]$} & 3 \\
\hline \multicolumn{3}{|c|}{ Acknowledgment of patient centeredness $[23,25,27-30,38,39,43,49,58]$} & 11 \\
\hline \multicolumn{3}{|c|}{ Specific relevance of patient centeredness to treatment outcomes $[26,28-37,39,41-43,45,47,50-57]$} & 25 \\
\hline
\end{tabular}

$H C V$ hepatitis $\mathrm{C}$ virus

${ }^{\text {a }}$ Studies that addressed more than one component of the dimension were counted once in the total dimension count 
two studies [33, 39], mental health and SAM services in three studies [35, 40, 51], specialty pharmacy [43], and other organizations for medication support [31].

\subsubsection{Continuity After Completing HCV Treatment To} prevent reinfection, four studies offered follow-ups after achieving SVR to assess reinfection [23, 37, 39, 56], one study included post-treatment risk reduction counseling [48], and another study offered reinfection information and sobriety support [44].

\subsubsection{Physical Comfort}

None of the included studies reported pain management activities, yet 14 studies provided physical comfort by supporting social needs (e.g., assisting with daily activities and living needs). Eight studies provided social services in addition to medical care including social case management [26, 31, 33, 39, 45, 47, 52, 58]. Two studies offered housing support in addition to income assistance [53] or legal support [32]. Two studies offered special housing support for homeless, or at risk of homelessness, patients [38, 44]. For incarcerated patients, one study offered court liaison to facilitate medical alternatives during incarceration [23], while another study coordinated with the justice system to ensure the ability of patients under legal procedures to adhere to HCV treatment [35].

\subsubsection{Information and Education}

Twenty-five studies offered information and education activities focusing on $\mathrm{HCV}$, while no study reported facilitating autonomy, self-care, or health promotion. Patient education took different forms; most settings offered direct education by providers and peers [23-25, 27-30, 32, 34, 35, 38, 39, 41, $42,47,49,50,52,53,55]$. Two settings offered educational counseling or psychoeducation $[36,51]$. One setting personalized its education to the patient's needs [45]. Two settings specified their education topics, the first targeted enhancing adherence via a 1-h information-motivation-behavioral skills intervention [46], while the second targeted reinfection prevention [44].

\subsubsection{Emotional Support}

Twenty studies offered patients support. Support teams included peers $[26,29,32,34,41,45,47,49,53,54,56$, 57], support groups [39], peers and clinical providers [50], behavioral or mental health specialists [33, 37, 51], and counselors [33, 35, 36, 48, 57].

\subsubsection{Involvement of Family and Friends}

Four studies reported involvement of family and friends for three aims: (a) accommodating treatment via education [27] or adherence support [23]; (b) HCV screening for patients' partners or direct contacts [24, 55]; and (c) including family members in treatment evaluation [55]. Unspecified support was mentioned in a fifth study under the term "buddy support" [34]. No study mentioned supporting caregiving.

\subsubsection{Respect for Patients' Values, Preferences, and Perceived Needs}

Nine studies reported addressing the patient values, preferences, or needs. Six studies involved the patient in developing personalized treatment and adherence plans $[31,36,51$, $52,57,58]$, and two studies personalized their education to the patient needs $[45,46]$. Only one study offered a space for shared decision making by discussing treatment options with their patients during the first visit [35]. No study reported activities for respecting the patient's cultural values and autonomy. Full description of patient-centeredness dimensions included in the analyzed studies is demonstrated in the ESM.

\subsection{Patient-Centeredness Recognition Elements in the Included Studies}

\subsubsection{Use of Patient-Centeredness Terminology}

Three studies referred to either "patient-centered" or "patient-centred" in describing their activities. One study referred to its $\mathrm{HCV}$ and HIV education component as patient centered [35], another study described its peer support group as patient centered [53], and the third study reported it used a patient-centered medical home model to treat homeless patients [54].

\subsubsection{Acknowledgment of Patient-Centeredness Importance}

Eleven studies acknowledged the importance of patient centeredness in their treatment delivery in different ways [23, 25, 27-30, 38, 39, 43, 49, 58]. Most commonly, these studies described implementing patient-centeredness dimensions as safe, feasible, and successful.

\subsubsection{Specific Relevance of Patient Centeredness to Treatment Outcomes}

Twenty-five studies described the relevance of patient centeredness to improved treatment outcomes [26, 28-37, 39, 41-43, 45, 47, 50-57]. These improvements spanned the 
HCV care continuum: screening and diagnosis rates, linkage to care, treatment uptake, adherence, and completion, achieving SVR, and preventing reinfection. A full description of patient-centeredness recognition elements in the analyzed studies is demonstrated in the ESM.

\section{Discussion}

To our knowledge, this is the first scoping review on patient centeredness in HCV DAA treatment delivery to PWID. Previous reviews on HCV treatment delivery to PWID in the DAA era focused on the effectiveness of communitybased delivery settings [59], treatment adherence facilitators [60], interventions supporting testing, linkage to care, and treatment uptake [61], and the impact of care integration on patient engagement in HCV treatment [62]. Our comprehensive review identified and assessed the inclusion of different dimensions of PCC in HCV treatment delivery to PWID during the DAA era. In addition, we identified how the included studies recognized patient centeredness and reported on its relevance to treatment outcomes.

We note that most of the included studies were recently published with increasing numbers over time. One possible reason for this increase over the years 2017-2019 is the change from the limited focus on the clinical efficacy of DAAs, to expanding on their real-world effectiveness and challenges. However, the limited scope is still obvious in the analyzed studies' aims and primary outcomes that focused on quantification rather than assessing the quality of treatment delivery and its patient centeredness. Most studies measured the numbers of patients across the HCV treatment continuum: screening, linkage to care, treatment adherence, treatment completion, SVR, and reinfection. Additionally, the included studies represent a variety of clinical settings in different regions of the world, with the use of primary care or SAM centers frequently because of their convenience to patients.

Overall, our findings highlight that PCC dimensions are prioritized differently and addressed using different approaches and strategies. There was no study in our review that addressed all eight dimensions of PCC. The most frequently included dimension "coordination and integration of care" pinpoints the compliance with the WHO guidelines and experts' recommendations on integrating HCV services with primary care services or other in-place services that support PWID with HCV to ensure responsiveness to their needs [12, 63]. The WHO recommends simplifying HCV service delivery models via decentralization of testing and treatment and integration with other services [12]. In the same line, the American Association for the Study of Liver Diseases guidance on PWID linkage to HCV care and treatment adherence recommends multidisciplinary delivery settings that offer services for managing social and psychiatric comorbidities and reducing the risk of reinfection [64]. A review on best practices for screening and delivering HCV treatment to PWID identified several benefits of SAM centers: quick diagnosis and initiation of targeted HCV education, familiarity of SAM centers staff with their patient' psychological needs, and better adherence and monitoring of HCV treatment when tied to SAM plans [65].

The "information and education" dimension was incorporated in several studies in different forms and levels starting from simple awareness messages to more in-depth counseling or psychoeducation. The absence of any study addressing information to facilitate autonomy, self-care, and health promotion may reflect either insufficient reporting in the included studies or their disproportionate focus on education messages that help ensure adherence to HCV treatment and reinfection prevention. The second possibility is supported by the frequent focus of the studies that included "continuity and translation" on follow-up and adherence support for HCV treatment.

The "emotional support" dimension of PCC was provided by different types of providers, peers, and support groups according to the availability and capacities of each delivery setting personnel. However, previous research revealed that emotional support from partners and family members was invaluable for PWID HCV treatment uptake and continuation [66].

The inclusion of "physical comfort" in several studies in this review implies that treatment delivery was guided by patients' profiles and social needs. Expert recommendations are given for early assessment of individual patient social profiles including housing, education level, cultural issues, social functioning and support, financial conditions, nutrition, and drug and alcohol use status. According to this comprehensive social assessment, PWID should be linked with relevant social support services [63]. Lack of support to pain management in the reviewed studies may be attributed to the natural history of $\mathrm{HCV}$ as a silent chronic infection that takes years to manifest its complications that may or may not include pain.

"Access to care" was addressed in an equal number of studies to "physical comfort". We observed that improving geographical accessibility was implemented via either transporting patients to services or task shifting of treatment to convenient pharmacies and primary care settings including virtual support via telemedicine. Assistance with scheduling and referral came next in addressing this dimension followed by activities that linked patients to specialty services.

"Respect for patients' values, preferences, and needs" came second to the least addressed dimension and revealed that respect was implemented using different approaches and at different points of care. However, no study in our review reported on activities that respect the patient cultural values 
and autonomy. Individual patient needs were addressed mainly via personalizing care, which aligns with the results of a recent qualitative study on HCV patients' experiences in integrated care settings that identified "caring", "collaborating", and "personalizing care to address individual needs" as three out of four elements of their PCC experience [67]. The single study [35] in our review that discussed treatment options with each patient at the first treatment visit neither described the decision space given to the patient nor reported if there was an agreement on shared outcomes between providers and patients. Shared decision making has been conceptualized as a continuum of decision space that ranges from physician- to patient-driven clinical decisions. The patient-driven end of the continuum gives the highest decision space to patients and their families where clinical providers offer expert knowledge and make no recommendations [68]. With regard to the shared decision concept, the patient-centered value framework of the National Health Council used the term "patient-integrated outcomes" to refer to shared outcomes driven by patients and consistent with their goals, aspirations, and experiences [69]. Evidence from the HCV literature pinpoints that HCV patients' desired outcomes are diverse and may be prioritized differently in comparison to those set by their providers. For instance, a panel of HCV patient experts agreed that patients seek treatment for several reasons including achieving cure, improving their quality of life, prolonging their life span, preventing complications, and reducing the risk of infecting others [70].

The least included dimension "involvement of family and friends" showed that comprehensive involvement is rarely included in DAA treatment delivery and its primary target is to ensure accommodation to treatment plans, specifically to ensure follow-up and adherence support. While this limited involvement of family and friends motivates treatment initiation and adherence, it misses further opportunities to strength and extend treatment benefits for PWID [71].

Across all studies, patient-centeredness terminology was mentioned in three occasions to describe education, peer support, or services for the homeless population. However, in these occasions, the meaning was close to "personalized activities," which does not necessarily imply the comprehensiveness of the PCC concept. About one-third of the studies acknowledged the importance of patient centeredness in their treatment delivery and two-thirds recognized its relevance to treatment outcomes. This recognition indicates that PCC is crucial for HCV treatment success and supports the need for more patient-centered PWID HCV treatment delivery.

Our review has some limitations. First, we included studies with published scientific articles that had full text available, excluding conference abstracts and organizational reports that may have included descriptions for $\mathrm{HCV}$ treatment delivery. Second, some included studies briefly described their delivery methods, which might have masked some details relevant to PCC dimensions. Additionally, included studies were conducted in a variety of healthcare settings with different types of PWID and care delivery methods. These differences may have impacted the articulation of patient-centeredness dimensions in their descriptions. Given these considerations, it can be expected that in the real world, the number of delivery methods and addressed PCC dimensions may be more than those analyzed in our review.

\section{Conclusions}

We mapped the inclusion of PCC dimensions in HCV treatment provision in the DAA era. None of the included studies addressed all eight dimensions of PCC, and their approaches to address each dimension were diverse reflecting each delivery setting capacity. Our results emphasize the need for more engagement of PWID in treatment decisions and outcomes, and comprehensive involvement of family and friends in the treatment journey. Future studies on HCV treatment delivery should detail how HCV treatment services are provided to PWID. Hepatitis $\mathrm{C}$ virus treatment effectiveness studies should not only quantify the clinical outcomes of DAA across the treatment continuum, but also assess PWID HCV treatment experiences and reported outcomes for better understanding of these clinical outcomes and their attributions. The results of this review should help guide $\mathrm{HCV}$ treatment providers and policy makers in developing effective patient-centered strategies and delivery methods to support elimination of HCV among PWID.

\section{Declarations}

Funding No financial support was received for the research, authorship, or publication of this article.

Conflict of interest Moaz Abdelwadoud, T. Joseph Mattingly II, Hemanuel Arroyo Seguí, Emily F. Gorman, and Eleanor M. Perfetto have no conflicts of interest that are directly relevant to the content of this article.

Ethics approval Not applicable.

Consent to participate Not applicable.

Consent for publication Not applicable.

Availability of data and material All data are available for revision as needed.

Code availability Not applicable.

Author contributions Moaz Abdelwadoud: project administration, conceptualization, methodology, investigation, formal analysis, data curation, writing the original draft. T. Joseph Mattingly II: conceptualization, formal analysis, validation, writing, reviewing, and editing. 
Hemanuel Arroyo Seguí: data curation, validation, investigation. Emily F. Gorman: methodology, software, resources. Eleanor M. Perfetto: conceptualization, supervision, writing, reviewing, and editing.

Open Access This article is licensed under a Creative Commons Attribution-NonCommercial 4.0 International License, which permits any non-commercial use, sharing, adaptation, distribution and reproduction in any medium or format, as long as you give appropriate credit to the original author(s) and the source, provide a link to the Creative Commons licence, and indicate if changes were made. The images or other third party material in this article are included in the article's Creative Commons licence, unless indicated otherwise in a credit line to the material. If material is not included in the article's Creative Commons licence and your intended use is not permitted by statutory regulation or exceeds the permitted use, you will need to obtain permission directly from the copyright holder. To view a copy of this licence, visit http://creativecommons.org/licenses/by-nc/4.0/.

\section{References}

1. Degenhardt L, Peacock A, Colledge S, Leung J, Grebely J, Vickerman $\mathrm{P}$, et al. Global prevalence of injecting drug use and sociodemographic characteristics and prevalence of HIV, HBV, and $\mathrm{HCV}$ in people who inject drugs: a multistage systematic review. Lancet Glob Health. 2017;5:e1192-207.

2. Grebely J, Larney S, Peacock A, Colledge S, Leung J, Hickman $\mathrm{M}$, et al. Global, regional, and country-level estimates of hepatitis $\mathrm{C}$ infection among people who have recently injected drugs. Addiction. 2019;114:150-66.

3. Abubakar II, Tillmann T, Banerjee A. Global, regional, and national age-sex specific all-cause and cause-specific mortality for 240 causes of death, 1990-2013: a systematic analysis for the Global Burden of Disease Study 2013. Lancet. 2015;385:117-71.

4. World Health Organization. Access to hepatitis $\mathrm{C}$ testing and treatment for people who inject drugs and people in prisons: a global perspective: policy brief. Geneva: World Health Organization; 2019.

5. Larney S, Grebely J, Hickman M, De Angelis D, Dore GJ, Degenhardt L. Defining populations and injecting parameters among people who inject drugs: implications for the assessment of hepatitis C treatment programs. Int J Drug Policy. 2015;26:950-7.

6. Talal AH, Thomas DL, Reynolds JL, Khalsa JH. Toward optimal control of hepatitis $\mathrm{C}$ virus infection in persons with substance use disorders. Ann Intern Med. 2017;897-8.

7. Grebely J, Bruneau J, Lazarus JV, Dalgard O, Bruggmann P, Treloar C, et al. Research priorities to achieve universal access to hepatitis $\mathrm{C}$ prevention, management and direct-acting antiviral treatment among people who inject drugs. Int J Drug Policy. 2017;47:51-60.

8. Jayadevappa R. Patient-centered outcomes research and patientcentered care for older adults: a perspective. Gerontol Geriatr Med. 2017;3:2333721417700759.

9. Kitson A, Marshall A, Bassett K, Zeitz K. What are the core elements of patient-centred care? A narrative review and synthesis of the literature from health policy, medicine and nursing. J Adv Nurs. 2013;69:4-15.

10. Kohn LT, Corrigan JM, Donaldson MS. Crossing the quality chasm: a new health system for the 21 st century. Washington, DC: National Academy Press; 2001.

11. Epstein RM. The science of patient-centered care. J Fam Pract. 2000;49:805-7.
12. World Health Organization. Guidelines for the care and treatment of persons diagnosed with chronic hepatitis $\mathrm{C}$ virus infection. Geneva: World Health Organization; 2018.

13. Rich KM, Bia J, Altice FL, Feinberg J. Integrated models of care for individuals with opioid use disorder: how do we prevent HIV and HCV? Curr HIV/AIDS Rep. 2018;15:266-75.

14. Martin NK, Hickman M, Hutchinson SJ, Goldberg DJ, Vickerman P. Combination interventions to prevent HCV transmission among people who inject drugs: modeling the impact of antiviral treatment, needle and syringe programs, and opiate substitution therapy. Clin Infect Dis. 2013;57:S39-45.

15. Bruggmann $\mathrm{P}$, Litwin AH. Models of care for the management of hepatitis $\mathrm{C}$ virus among people who inject drugs: one size does not fit all. Clin Infect Dis. 2013;57:S56-61.

16. Rudzinski K, McDonough P, Gartner R, Strike C. Is there room for resilience? A scoping review and critique of substance use literature and its utilization of the concept of resilience. Subst Abuse Treat Prev Policy. 2017;12:41.

17. Tricco AC, Lillie E, Zarin W, O’Brien KK, Colquhoun H, Levac $\mathrm{D}$, et al. PRISMA extension for scoping reviews (PRISMA-ScR): checklist and explanation. Ann Intern Med. 2018;169:467-73.

18. Hajarizadeh B, Cunningham EB, Reid H, Law M, Dore GJ, Grebely J. Direct-acting antiviral treatment for hepatitis $\mathrm{C}$ among people who use or inject drugs: a systematic review and metaanalysis. Lancet Gastroenterol Hepatol. 2018;3:754-67.

19. Ouzzani M, Hammady H, Fedorowicz Z, Elmagarmid A. Rayyan-a web and mobile app for systematic reviews. Syst Rev. 2016;5:210.

20. Gerteis M, Edgman-Levitan S, Daley J, Delbanco TL. Through the patient's eyes: understanding and promoting patient-centered care. San Francisco: Jossey-Bass Publishers Inc; 1993.

21. One View. The Eight Principles of Patient-Centered Care [Internet]. 2015 [cited 2019 Apr 12]. https://www.oneviewhealthca re.com/the-eight-principles-of-patient-centered-care/.

22. Robinson JH, Callister LC, Berry JA, Dearing KA. Patient-centered care and adherence: definitions and applications to improve outcomes. J Am Acad Nurse Pract. 2008;20:600-7.

23. Akiyama MJ, Columbus D, MacDonald R, Jordan AO, Schwartz $\mathrm{J}$, Litwin $\mathrm{AH}$, et al. Linkage to hepatitis $\mathrm{C}$ care after incarceration in jail: a prospective, single arm clinical trial. BMC Infect Dis. 2019;19:703.

24. Mangia A. Puglia HCV Micro-elimination Program [Internet]. 2019 [cited 2020 Mar 2]. https://www.clinicaltrials.gov/ct2/show/ results/NCT03923595?view=results.

25. Radley A, Tait J, Dillon JF. DOT-C: a cluster randomised feasibility trial evaluating directly observed anti-HCV therapy in a population receiving opioid substitute therapy from community pharmacy. Int J Drug Policy. 2017;47:126-36.

26. Bajis S, Grebely J, Cooper L, Smith J, Owen G, Chudleigh A, et al. Hepatitis $\mathrm{C}$ virus testing, liver disease assessment and directacting antiviral treatment uptake and outcomes in a service for people who are homeless in Sydney, Australia: the LiveRLife homelessness study. J Viral Hepat. 2019;26:969-79.

27. Dhiman RK, Grover GS, Premkumar M, Taneja S, Duseja A, Arora S, et al. Decentralized care with generic direct-acting antivirals in the management of chronic hepatitis $\mathrm{C}$ in a public health care setting. J Hepatol. 2019;71:1076-85.

28. Talal AH, Andrews P, Mcleod A, Chen Y, Sylvester C, Markatou $\mathrm{M}$, et al. Integrated, co-located, telemedicine-based treatment approaches for hepatitis $\mathrm{C}$ virus management in opioid use disorder patients on methadone. Clin Infect Dis. 2019;69:323-31.

29. Talal AH, McLeod A, Andrews P, Nieves-McGrath H, Chen Y, Reynolds A, et al. Patient reaction to telemedicine for clinical management of hepatitis $\mathrm{C}$ virus integrated into an opioid treatment program. Telemed J E Health. 2019;25:791-801. 
30. Papaluca T, McDonald L, Craigie A, Gibson A, Desmond P, Wong $\mathrm{D}$, et al. Outcomes of treatment for hepatitis $\mathrm{C}$ in prisoners using a nurse-led, statewide model of care. J Hepatol. 2019;70:839-46.

31. Read P, Lothian R, Chronister K, Gilliver R, Kearley J, Dore GJ, et al. Delivering direct acting antiviral therapy for hepatitis $\mathrm{C}$ to highly marginalised and current drug injecting populations in a targeted primary health care setting. Int J Drug Policy. 2017;47:209-15.

32. Stagg HR, Surey J, Francis M, MacLellan J, Foster GR, Charlett $\mathrm{A}$, et al. Improving engagement with healthcare in hepatitis $\mathrm{C}$ : a randomised controlled trial of a peer support intervention. BMC Med. 2019;17:71.

33. Woodrell C, Weiss J, Branch A, Gardenier D, Krauskopf K, Kil N, et al. Primary care-based hepatitis C treatment outcomes with first-generation direct-acting agents. J Addict Med. 2015;9:405-10.

34. Harrison GI, Murray K, Gore R, Lee P, Sreedharan A, Richardson $\mathrm{P}$, et al. The hepatitis $\mathrm{C}$ awareness through to treatment (HepCATT) study: improving the cascade of care for hepatitis $\mathrm{C}$ virus-infected people who inject drugs in England. Addiction. 2019;114:1113-22.

35. Burton MJ, Voluse AC, Anthony V. Integrating comprehensive hepatitis $\mathrm{C}$ virus care within a residential substance use disorder treatment program. J Subst Abuse Treat. 2019;98:9-14.

36. Norton BL, Fleming J, Bachhuber MA, Steinman M, DeLuca J, Cunningham CO, et al. High HCV cure rates for people who use drugs treated with direct acting antiviral therapy at an urban primary care clinic. Int J Drug Policy. 2017;47:196-201.

37. Groessl EJ, Liu L, Sklar M, Ho SB. HCV integrated care: a randomized trial to increase treatment initiation and SVR with direct acting antivirals. Int J Hepatol. 2017;2017:5834182.

38. Harney BL, Whitton B, Lim C, Paige E, McDonald B, Nolan S, et al. Quantitative evaluation of an integrated nurse model of care providing hepatitis $\mathrm{C}$ treatment to people attending homeless services in Melbourne, Australia. Int J Drug Policy. 2019;72:195-8.

39. Alimohammadi A, Holeksa J, Thiam A, Truong D, Conway B. Real-world efficacy of direct-acting antiviral therapy for $\mathrm{HCV}$ infection affecting people who inject drugs delivered in a multidisciplinary setting. Open Forum Infect Dis. 2018;5:ofy 120.

40. Ramachandran J, Budd S, Slattery H, Muller K, Mohan T, Cowain $\mathrm{T}$, et al. Hepatitis $\mathrm{C}$ virus infection in Australian psychiatric inpatients: a multicenter study of seroprevalence, risk factors and treatment experience. J Viral Hepat. 2019;26:609-12.

41. Bonnington $\mathrm{O}$, Harris $\mathrm{M}$. Tensions in relation: how peer support is experienced and received in a hepatitis $\mathrm{C}$ treatment intervention. Int J Drug Policy. 2017;47:221-9.

42. Wade AJ, Doyle JS, Gane E, Stedman C, Draper B, Iser D, et al. Outcomes of treatment for hepatitis $\mathrm{C}$ in primary care compared to hospital-based care: a randomised controlled trial in people who inject drugs. Clin Infect Dis. 2020;70:1900-6.

43. Rizk C, Miceli J, Shiferaw B, Malinis M, Barakat L, Ogbuagu $\mathrm{O}$, et al. Implementing a comprehensive hepatitis $\mathrm{C}$ virus (HCV) clinic within a human immunodeficiency virus clinic: a model of care for HCV microelimination. Open Forum Infect Dis. 2019;6:ofz361.

44. Trabut JB, Barrault C, Charlot H, Carmona D, Bourdel A, Benslimane $\mathrm{M}$, et al. Integrated care for the use of direct-acting antivirals in patients with chronic hepatitis $\mathrm{c}$ and substance use disorder. J Addict Med. 2018;12:346-52.

45. Eckhardt BJ, Scherer M, Winkelstein E, Marks K, Edlin BR. Hepatitis $\mathrm{C}$ treatment outcomes for people who inject drugs treated in an accessible care program located at a syringe service program. Open Forum Infect Dis. 2018;5:ofy048.

46. Inglis SK, Beer LJ, Byrne C, Malaguti A, Robinson E, Sharkey C, et al. Randomised controlled trial conducted in injecting equipment provision sites to compare the effectiveness of different hepatitis $\mathrm{C}$ treatment regimens in people who inject drugs: A Direct obserVed therApy versus fortNightly CollEction study for HCV treatment-ADVANCE HCV protocol study. BMJ Open. 2019;9:e029516.

47. Kikvidze T, Luhmann N, Avril E, Butsashvili M, Labartkava K, Etienne A, et al. Harm reduction-based and peer-supported hepatitis $\mathrm{C}$ treatment for people who inject drugs in Georgia. Int J Drug Policy. 2018;52:16-9.

48. Coffin PO, Santos G-M, Behar E, Hern J, Walker J, Matheson $\mathrm{T}$, et al. Randomized feasibility trial of directly observed versus unobserved hepatitis $C$ treatment with ledipasvir-sofosbuvir among people who inject drugs. PLoS One. 2019;14:e0217471.

49. Ward KM, Falade-Nwulia O, Moon J, Sutcliffe CG, Brinkley S, Haselhuhn T, et al. A randomized controlled trial of cash incentives or peer support to increase HCV treatment for persons with HIV who use drugs: the CHAMPS Study. Open Forum Infect Dis. 2019;6:ofz166.

50. Akiyama MJ, Norton BL, Arnsten JH, Agyemang L, Heo M, Litwin AH. Intensive models of hepatitis $\mathrm{C}$ care for people who inject drugs receiving opioid agonist therapy a randomized controlled trial. Ann Intern Med. 2019;170:594-603.

51. Bartholomew TS, Grosgebauer K, Huynh K, Cos T. Integration of hepatitis $\mathrm{C}$ treatment in a primary care federally qualified health center; Philadelphia, Pennsylvania, 2015-2017. Infect Dis Res Treat. 2019;12:1178633719841381.

52. Read P, Gilliver R, Kearley J, Lothian R, Cunningham EB, Chronister KJ, et al. Treatment adherence and support for people who inject drugs taking direct-acting antiviral therapy for hepatitis $\mathrm{C}$ infection. J Viral Hepat. 2019;26:1301-10.

53. Selfridge M, Cunningham EB, Milne R, Drost A, Barnett T, Lundgren $\mathrm{K}$, et al. Direct-acting antiviral treatment for hepatitis $\mathrm{C}$, reinfection and mortality among people attending an inner-city community health centre in Victoria, Canada. Int J Drug Policy. 2019;72:106-13.

54. Williams BE, Nelons D, Seaman A, Witkowska M, Ronan W, Wheelock $\mathrm{H}$, et al. Life projects: the transformative potential of direct-acting antiviral treatment for hepatitis $\mathrm{C}$ among people who inject drugs. Int J Drug Policy. 2019;72:138-45.

55. Butner JL, Gupta N, Fabian C, Henry S, Shi JM, Tetrault JM. Onsite treatment of HCV infection with direct acting antivirals within an opioid treatment program. J Subst Abuse Treat. 2017;75:49-53.

56. Bouscaillou J, Kikvidze T, Butsashvili M, Labartkava K, Inaridze I, Etienne A, et al. Direct acting antiviral-based treatment of hepatitis $\mathrm{C}$ virus infection among people who inject drugs in Georgia: a prospective cohort study. Int J Drug Policy. 2018;62:104-11.

57. Falade-Nwulia O, Sutcliffe C, Moon J, Chander G, Wansom T, Keruly J, et al. High hepatitis $\mathrm{C}$ cure rates among black and nonblack human immunodeficiency virus-infected adults in an urban center. Hepatology. 2017;66:1402-12.

58. Chronister KJ, Lothian R, Gilliver R, Kearley J, Read P. Feasibility and acceptability of adherence support for direct acting antiviral therapy for hepatitis $\mathrm{C}$ in a low-threshold primary health-care opioid agonist treatment program. Drug Alcohol Rev. 2019;38:185-9.

59. Pourmarzi D, Hall L, Hepworth J, Smirnov A, Rahman T, FitzGerald G. Clinical effectiveness, cost effectiveness and acceptability of community-based treatment of hepatitis $\mathrm{C}$ virus infection: a mixed method systematic review. J Viral Hepat. 2019;26:432-53.

60. Rich ZC, Chu C, Mao J, Zhou K, Cai W, Ma Q, et al. Facilitators of HCV treatment adherence among people who inject drugs: a systematic qualitative review and implications for scale up of direct acting antivirals. BMC Public Health. 2016;16:994.

61. Bajis S, Dore GJ, Hajarizadeh B, Cunningham EB, Maher L, Grebely J. Interventions to enhance testing, linkage to care and treatment uptake for hepatitis $\mathrm{C}$ virus infection among 
people who inject drugs: a systematic review. Int J Drug Policy. 2017;47:34-46.

62. Socías ME, Karamouzian M, Parent S, Barletta J, Bird K, Ti L. Integrated models of care for people who inject drugs and live with hepatitis $\mathrm{C}$ virus: a systematic review. Int J Drug Policy. 2019;72:146-59.

63. Grebely J, Robaeys G, Bruggmann P, Aghemo A, Backmund M, Bruneau J, et al. Recommendations for the management of hepatitis $\mathrm{C}$ virus infection among people who inject drugs. Int J Drug Policy. 2015;26:1028-38.

64. American Association for the Study of Liver Diseases. Key populations: identification and management of hov in people who inject drugs [Internet]. HCV Guid. Recomm. Testing, Manag. Treat. Hepat. C. 2019 [cited 2020 Aug 21]. https://www.hcvguidelines. org/unique-populations/pwid

65. Norton BL, Akiyama MJ, Zamor PJ, Litwin AH. Treatment of chronic hepatitis $\mathrm{C}$ in patients receiving opioid agonist therapy: a review of best practice. Infect Dis Clin. 2018;32(2):347-70.

66. Harris M, Jolly E, Martin A, Wells H, Rhodes T. Barriers and facilitators to hepatitis $\mathrm{C}$ treatment for people who inject drugs: a qualitative study. Copenhagen: World Health Organization Regional Office of Europe; 2012.

67. Youssef A, Wiljer D, Mylopoulos M, Maunder R, Sockalingam S. "Caring about me": a pilot framework to understand patient-centered care experience in integrated care: a qualitative study. BMJ Open. 2020;10:e034970.

68. Kon AA. The shared decision-making continuum. JAMA. 2010;304:903-4.

69. Perfetto EM, Oehrlein EM, Boutin M, Reid S, Gascho E. Value to whom? The patient voice in the value discussion. Value Health. 2017;20:286-91.

70. Mattingly TJ II, Slejko JF, Perfetto EM, Kottilil S, Mullins CD. What matters most for treatment decisions in hepatitis C: effectiveness, costs, and altruism. Patient. 2019;12:631-8.

71. National Institutes of Health. National Institute on Drug Abuse. Principles of drug addiction treatment: a research-based guide, 3rd ed. National Institutes of Health, National Institute on Drug Abuse; 2018.

72. Heath B, Wise Romero P, Reynolds K. A review and proposed standard framework for levels of integrated healthcare. Washington, DC: SAMHSA-HRSA Center for Integrated Health Solutions; 2013. 